\title{
Chylous ascites associated with intestinal obstruction from volvulus due to Petersen's hernia: report of a case
}

\author{
Yuichi Akama*, Tetsuya Shimizu, Itsuo Fujita, Yoshikazu Kanazawa, Daisuke Kakinuma, Hitoshi Kanno, \\ Aya Yamagishi, Hiroki Arai and Eiji Uchida
}

\begin{abstract}
Background: Chylous ascites is an uncommon finding which is usually associated with recent abdominal/ oncologic or retroperitoneal surgery. It is not usually seen in cases of acute obstruction.

Case presentation: A patient who had previously undergone a laparoscopy-assisted distal gastrectomy with Rouxen-Y reconstruction for early gastric cancer presented with acute abdominal pain and epigastric fullness. Computed tomography suggested small bowel obstruction due to volvulus. We were able to reduce the volvulus and close a Petersen's hernia without resecting the bowel; a large amount of chylous ascites was an incidental finding.

Conclusions: We present a case of chylous ascites occurring in a setting of small bowel obstruction due to Petersen's hernia, 3 years after successful distal gastrectomy for early gastric cancer, with no evidence of tumor recurrence.
\end{abstract}

Keywords: Chylous ascites, Intestinal obstruction, Ischemia

\section{Background}

A large amount of ascites can accompany bowel obstruction with nonviable bowel loops [1]. Ascites is occasionally bloody [2] and can be seen in obstruction cases requiring intestinal resection. Chylous ascites, however, has not been commonly observed with bowel obstruction. Here, we report a case of a large amount of chylous ascites associated with small bowel obstruction from a Petersen's hernia-associated volvulus, which was successfully treated without bowel resection.

\section{Case presentation}

An 85-year-old man presented to our hospital with a 5-h history of abdominal pain and distention. He attended the outpatient department at our hospital for regular checkups but had been asymptomatic until he visited out emergency department. At age 82 years, he had undergone laparoscopy-assisted distal gastrectomy with Roux-en-Y reconstruction for early gastric cancer. An

\footnotetext{
* Correspondence: y-akama@nms.ac.jp

Department of Gastrointestinal and Hepato-Biliary-Pancreatic Surgery,

Nippon Medical School Hospital, 1-1-5 Sendagi, Bunkyo-Ku, Tokyo, Japan
}

antecolic isoperistaltic gastrojejunostomy was performed using an endoscopic linear stapler. A serosubmucosal single-layer hand-sewn anastomosis (Jourdan's) was performed through a small abdominal incision for $\mathrm{Y}$ reconstruction. The mesentery of the $Y$ loop was closed using nonabsorbable braided polyester (3-0) interrupted sutures, while the Petersen's defect was not closed. Pathology revealed a stage IB (T2NOM0) tumor; the resection stumps were negative. His postoperative course had been unremarkable. Computed tomography (CT) performed 1.5 months prior to admission showed no evidence of tumor recurrence and no ascites. The patient had no other relevant medical history.

Physical examination on arrival showed focal tenderness and distention in the epigastrium. His body temperature was $36.4{ }^{\circ} \mathrm{C}$.

Laboratory data were unremarkable except for a white blood cell $(\mathrm{WBC})$ count of $8.7 \times 10^{9}$ cells/L (normal, $4.0-8.0 \times 10^{9}$ cells/L) and a C-reactive protein (CRP) level of $16.2 \mathrm{nmol} / \mathrm{L}$ (normal, $<2.9 \mathrm{nmol} / \mathrm{L}$ ). A contrastenhanced abdominal CT scan (Fig. 1) showed dilation of the transverse colon, severe ascites, and a whorl-like 


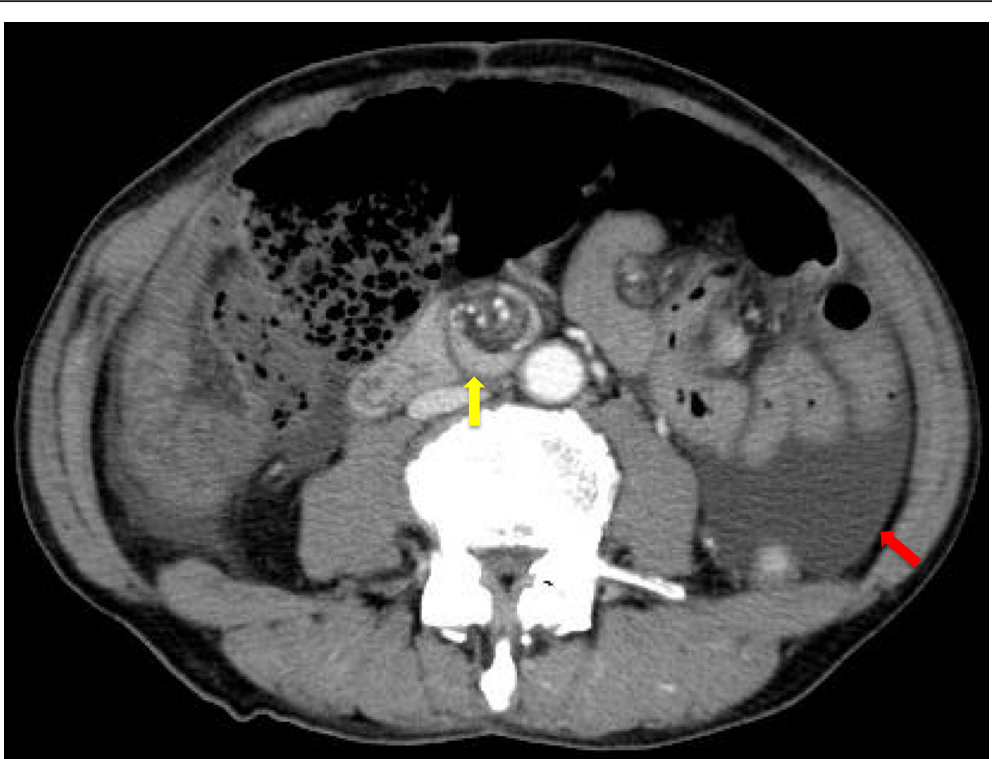

Fig. 1 CT scan showing a large amount of ascites (red arrow) and whorl-like appearance of the superior mesenteric artery (SMA) and branches with adjacent collapsed loops of small bowel (yellow arrow)

appearance of the superior mesenteric artery (SMA) and branches wrapped with adjacent mesentery and small bowel loops (the "whirl" or "whorl" sign) [3], which is characteristic of small bowel volvulus. Given these findings, we performed emergency laparotomy.

Intraoperatively, a massive amount of milky fluid was observed in the peritoneal cavity, and approximately $1 \mathrm{~L}$ was removed (Fig. 2). The greater part of the small bowel passed through the defect between the jejunal mesentery and the mesocolon (Petersen's defect). The small intestine was displaced to the left and was obstructed due to jejunal volvulus (Fig. 3). The jejunum was rotated $180^{\circ}$ counterclockwise around its long axis and compressed the transverse colon. The entire small bowel was edematous but viable, with no evidence of a mobile cecum, peritoneal tumor, or perforation. The

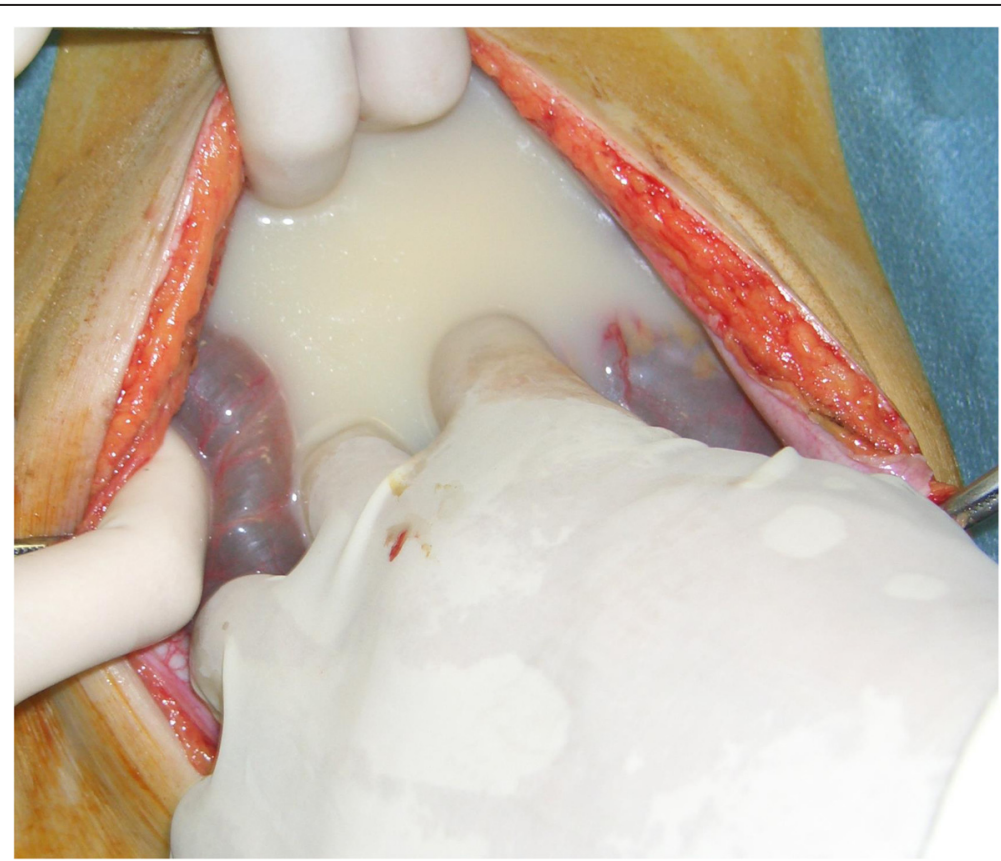

Fig. 2 Milky fluid in the peritoneal cavity 


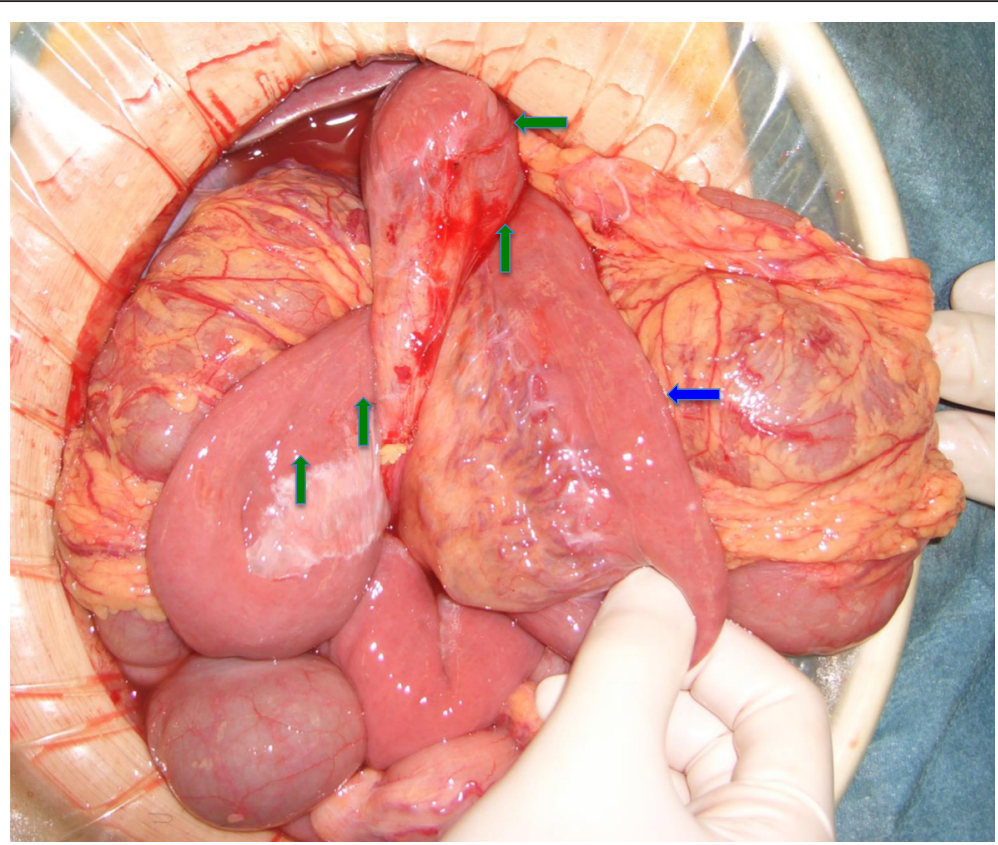

Fig. 3 The small bowel passes through the defect between the jejunal mesentery (blue arrow) and the mesocolon. The jejunum was rotated $180^{\circ}$ counterclockwise in the direction of the long axis (green arrows)

volvulus and internal hernia were reduced, and the Petersen's defect was sutured closed. No bowel resection was required. Extensive lavage of the abdominal cavity was performed until the return fluid was clear, and intraperitoneal drains were placed in the rectovesical pouch and under the right hemidiaphragm. The triglyceride (TG) level of the ascitic fluid was $642 \mathrm{mg} / \mathrm{dL}$. The cultures and cytology of the peritoneal fluid were negative for infection and malignancy, respectively.

The patient's postoperative course was uneventful. The color of the ascites changed from milky to light yellow, and the TG levels decreased to $21 \mathrm{mg} / \mathrm{dL}$ on postoperative day
4. The patient was not required to eat a fat-restricted diet during hospitalization and was discharged from the hospital 16 days after surgery. He underwent a physical examination and CT scan in the outpatient department 10 months after discharge from the hospital. There was no evidence of ascites (Fig. 4). He had made favorable progress by the time of the 28-month postoperative follow-up, with evidence of weight gain and no evidence of recurrent ascites (Fig. 5).

\section{Discussion}

Chylous ascites typically develops due to congestion of the lymphatic system. Malignancy-particularly lymphoma-is

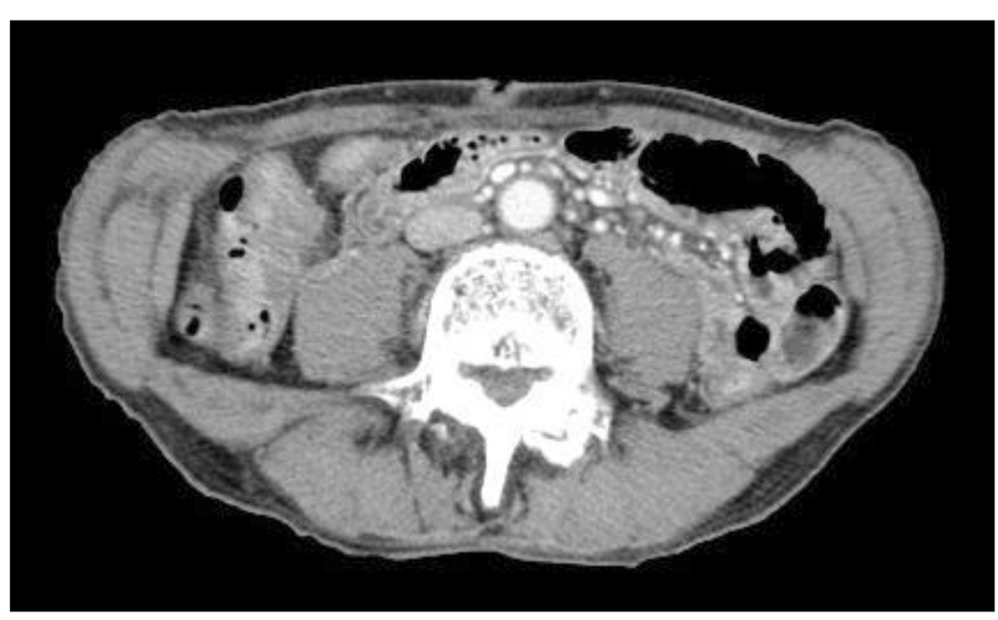

Fig. $4 \mathrm{CT}$ performed 10 months after surgery shows no evidence of the recurrence of ascites 


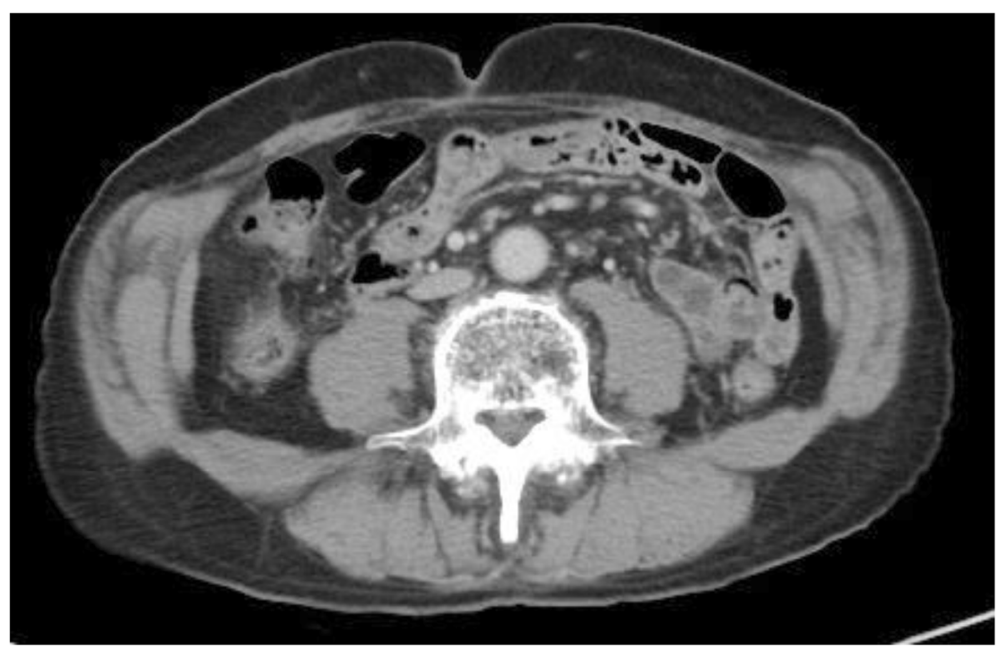

Fig. 5 CT performed 28 months after surgery shows increasing subcutaneous fat, indicating improvement in the patient's health

a relatively common cause of chylous ascites in adults [4]. Metastasis of the malignancy into the lymphatic channels and the resulting occlusions can cause leakage from the dilated subserosal lymphatic system into the peritoneal cavity $[5,6]$. However, there have been few reports of chylous ascites associated with intestinal obstruction [7].

In the present case, an abdominal CT scan showed a dilated colon and severe ascites with a whorl-like appearance of the SMA and mesentery, findings generally suggesting small bowel obstruction from volvulus $[3,8]$, which may be strangulated $[1,9]$. High TG levels, typically $>200 \mathrm{mg} / \mathrm{dL}$, in the ascitic fluid are critical in defining chylous ascites [10]. Given that our patient had TG levels exceeding $600 \mathrm{mg} / \mathrm{dL}$, the milky fluid was diagnosed as chylous ascites. The CT value of the ascites was 5.0 HU, not suggestive of hemoperitoneum and indistinguishable from that of water [11-13]. Major lymphatic leaks can sometimes be visualized with MR lymphography [14], aiding the diagnosis of chylous ascites. However, minor leaks may be undetectable. After surgery to repair the internal hernia, the TG levels decreased from 642 to $21 \mathrm{mg} / \mathrm{dL}$ without any ligation of lymph vessels or dietary restriction. These observations prompted us to diagnose the patient as having chylous ascites associated with small bowel obstruction.

We identified eight case reports of chylous ascites with bowel obstruction in the English language literature (Table 1). Chylous ascites associated with intestinal obstruction was first mentioned by Mackman in 1967, and our present case is the first case report of chylous ascites occurring with a Petersen's hernia. As in our case, all previous cases were characterized by the presence of small bowel obstruction. Detecting a cause of chylous ascites associated with bowel obstruction is difficult, because these cases are so rare. Of note, however, no previous studies [15-22] reported the requirement for an

Table 1 Overview of previously reported cases of intestinal obstruction with chylous ascites; no case needed resection

\begin{tabular}{|c|c|c|c|c|c|}
\hline $\begin{array}{l}\text { Author [ref } \\
\text { number] }\end{array}$ & Age, sex & Preoperative diagnosis & Cause of obstruction & Surgery & $\begin{array}{l}\text { Postoperative } \\
\text { course }\end{array}$ \\
\hline Mackman [15] & $\begin{array}{l}30 \text { months, } \\
\mathrm{M}\end{array}$ & Distended abdomen, unknown etiology & Midgut volvulus & Reduction and cecopexy & Uneventful \\
\hline Shariff [16] & 7 weeks, $M$ & Reducible inguinal hernia & Midgut volvulus & $\begin{array}{l}\text { Reduction and Ladd's } \\
\text { procedure }\end{array}$ & Uneventful \\
\hline Murugan [17] & $44, \mathrm{M}$ & Small bowel volvulus & Small bowel volvulus & Reduction & Uneventful \\
\hline Seltz [18] & 2 weeks, M & Midgut volvulus & Midgut volvulus & $\begin{array}{l}\text { Reduction and Ladd's } \\
\text { procedure }\end{array}$ & Uneventful \\
\hline Zarroug [19] & 12 weeks, $M$ & Midgut volvulus & Midgut volvulus & $\begin{array}{l}\text { Reduction and Ladd's } \\
\text { procedure }\end{array}$ & Uneventful \\
\hline Hidalgo [20] & $40, M$ & $\begin{array}{l}\text { Chronic abdominal pain post laparoscopic } \\
\text { Roux-en-Y gastric bypass surgery }\end{array}$ & $\begin{array}{l}\text { Internal hernia of common } \\
\text { channel }\end{array}$ & Reduction & Uneventful \\
\hline Pengelly [21] & $85, F$ & Acute abdomen & Small bowel volvulus & Reduction & Uneventful \\
\hline Koh [22] & $19, M$ & Small bowel volvulus & Small bowel volvulus & Reduction & Uneventful \\
\hline
\end{tabular}


enterectomy, and their postoperative courses were uneventful.

The abdominal CT scan showed that there was an intestinal obstruction and large amounts of ascites. These findings sometimes indicate strangulated obstruction. Our case was interesting in that the physical examination and laboratory tests did not match the severity of the problem as shown on CT. It is difficult to explain this discrepancy, and it is difficult to prove accurately what caused the chylous ascites. This situation is very rare. The absence of bowel ischemia suggests that the arteriovenous system was patent while lymphatic channels were occluded in this case. This vascular patency may explain the discrepancy between the laboratory values and physical findings and the imaging findings, and the fact that no previous cases have reported the requirement for an enterectomy. The obstruction of the lymphatic system resulted in the extravasation of chylous fluid [23]. Pre- and intraoperative evaluation of ascites may be helpful in making decisions concerning therapeutic strategies, because bowel obstruction with chylous ascites may indicate intestinal viability.

\section{Conclusions}

We present a case of chylous ascites associated with intestinal obstruction from volvulus due to a Petersen's hernia. Detecting the presence of chylous ascites in small bowel obstruction is important, because the therapeutic strategy may differ depending on it. The presence of chylous ascites with intestinal obstruction may represent a particular situation in which the arteriovenous system is patent, and more conservative therapy may be appropriate.

\section{Consent}

Written informed consent was obtained from the patient's family for the publication of this case report and any accompanying images. A copy of the written consent is available for review from the Editor-in-Chief of this journal.

\section{Abbreviations}

CRP, C-reactive protein; $C T$, computed tomography; HU, Hounsfield Units; SMA, superior mesenteric artery; TG, triglycerides; WBC, white blood cell count

\section{Competing interest}

The authors declare no competing interest associated with this manuscript.

\section{Authors' contributions}

YA, TS, and AY performed the surgery and wrote the paper. DK, HK, and HA cared for the patient and generated the figures and table. EU, IF, and YK contributed to the manuscript revision and had final approval of the article. All authors discussed the results and commented on the manuscript. All authors read and approved the final manuscript.

\section{Funding}

The authors received no funding for this paper.
Received: 25 May 2016 Accepted: 23 July 2016

Published online: 28 July 2016

\section{References}

1. Takahashi R, Akagi Y, Tanaka T, Kaibara A, Kajiwara S, Shima I, et al. Clinicopathological evaluation of anoxic mucosal injury in strangulation ileus. BMC Surg. 2014;14:79.

2. Kobayashi S, Matsuura K, Matsushima K, Okubo K, Henzan E, Maeshiro M. Effectiveness of diagnostic paracentesis and ascites analysis for suspected strangulation obstruction. J Gastrointest Surg. 2007;11:240-6.

3. Khurana B. The whirl sign. Radiology. 2003;226:69-70.

4. Press OW, Press NO, Kaufman SD. Evaluation and management of chylous ascites. Ann Intern Med. 1982;96:358-64.

5. Browse NL, Wilson NM, Russo F, al-Hassan H, Allen DR. Aetiology and treatment of chylous ascites. Br J Surg. 1992:79:1145-50.

6. Almakdisi T, Massoud S, Makdisi G. Lymphomas and chylous ascites: review of the literature. Oncologist. 2005;10:632-5.

7. Steinemann DC, Dindo D, Clavien P-A, Nocito A. Atraumatic chylous ascites: systematic review on symptoms and causes. J Am Coll Surg. 2011;212:899-905.e1-4.

8. Gollub MJ, Yoon S, Smith LM, Moskowitz CS. Does the CT whirl sign really predict small bowel volvulus? Experience in an oncologic population. J Comput Assist Tomogr. 2006;30:25-32.

9. Kim JH, Ha HK, Kim JK, Eun HW, Park KB, Kim BS, et al. Usefulness of known computed tomography and clinical criteria for diagnosing strangulation in small-bowel obstruction: analysis of true and false interpretation groups in computed tomography. World J Surg. 2004;28:63-8.

10. Cárdenas A, Chopra S. Chylous ascites. Am J Gastroenterol. 2002;97:1896-900.

11. Fujita N, Noda Y, Kobayashi G, Kimura K, Watanabe H, Masu K, et al. Chylous cyst of the mesentery: US and CT diagnosis. Abdom Imaging. 1995;20:259-61.

12. Becker $C D$, Mentha $G$, Terrier F. Blunt abdominal trauma in adults: role of $C T$ in the diagnosis and management of visceral injuries Part 1: liver and spleen. Eur Radiol. 1998;8:553-62.

13. Gore RM, Silvers RI, Newmark GM, Gore MD. Ascites and peritoneal fluid collections. In: Gore RM, Levine MS, editors. Textbook of Gastrointestinal Radiology. 4th ed. Philadelphia: W. B. Saunders Company; 2014. p. 2029-31.

14. Arive L, Azizi L, Lewin M, Hoteffel C, Monnier-Cholley L, Lacombe C, et al. MR lymphography of abdominal and retroperitoneal lymphatic vessels. AJR Am J Roentgenol. 2007;189:1051-8.

15. Mackman S, Milburn WH, Pellett JR, Lemmer KE. Chylous ascites associated with malrotation of the intestines. Am J Surg. 1967;113:282-4.

16. Shariff FU, Curry J, De Coppi P, Drake DP. Laparoscopic finding of chylous ascites and intestinal malrotation in an infant presenting with left inguinal hernia. J Laparoendosc Adv Surg Tech. 2008;18:651-3.

17. Murugan K, Spence RAJ. Chylous peritonitis with small bowel obstruction. Ulster Med J. 2008:77:132-3.

18. Seltz LB, Kanani R, Zamakhshary M, Chiu PPL. A newborn with chylous ascites caused by intestinal malrotation associated with heterotaxia syndrome. Pediatr Surg Int. 2008;24:633-6.

19. Zarroug $A E$, Srinivasan SK, Wulkan ML. Incidental chylous fluid during hernia repair may be a harbinger of malrotation. J Pediatr Surg. 2010;45:E17-18.

20. Hidalgo JE, Ramirez A, Patel S, Acholonu E, Eckstein J, Abu-Jaish W, et al. Chyloperitoneum after laparoscopic Roux-en-Y gastric bypass (LRYGB). Obes Surg. 2010;20:257-60.

21. Pengelly S, Potiszil K, Feldman M. Spontaneous midgut volvulus causing chylous ascites in an octogenarian. BMJ Case Rep; 2012. doi: 10.1136/bcr-2012-006950

22. Koh YX, Chng JK, Tan HC, Chung AYF. Intestinal torsion causing chylous ascites: a rare occurrence. Singapore Med J. 2013;54:e88-90.

23. Aalami OO, Allen DB, Organ Jr CH. Chylous ascites: a collective review. Surgery. 2000;128:761-78. 